\title{
WS6-C03
}

\section{The Interpacific Project - A Cooperative Exercise for Assessing Reliability and Accuracy of Seismic Methods}

\author{
F. Hollender (CEA), P.Y. Bard (IS-terre), C. Cornou (IS-terre), B.R. Cox (UT \\ Austin), S. Foti* (Politecnico di Torino), F. Garofalo (Politecnico di Torino), \\ M. Ohrnberger (University of Potsdam) \& D. Sicilia (EdF)
}

\section{SUMMARY}

The InterPacific (Intercomparison of methods for site parameter and velocity profile characterization) project aims to assess the reliability/variability of seismic site characterization methods (borehole and surface wave methods) used for estimating shear wave velocity (Vs) profiles and corresponding lumped parameters (e.g., Vs,30). The ultimate goal of the project is to determine procedures that can be used for the construction of consistent ground models for seismic studies. Three sites have been selected in France and Italy for the implementation of the project. They are representative of different geological conditions relevant for the evaluation of seismic site response effects: a stiff rock outcrop, a deep soft deposit, and an intermediate case with thick stiff soils and large bedrock depth. 


\section{Amsterdam ' 14}

\section{Introduction}

In recent years, the use of surface wave tests for seismic site characterization has expanded rapidly in the field of applied seismology and earthquake engineering. Indeed these methods are cost and time effective with respect to the invasive ones, which require the use of boreholes.

For surface wave methods, difficult and onerous interpretation and inversion processes are needed to derive a reliable $\mathrm{S}$-wave velocity $\left(\mathrm{V}_{\mathrm{S}}\right)$ profile. At the same time, the availability of affordable seismic equipment and "black-box" processing software has led to a wide diffusion of surface wave methods among inexperienced analysts. The combination of the aforementioned factors induces in the final user (i.e., the engineer or the seismologist who require the shear wave velocity model) a lack of confidence in results obtained from surface wave testing. On the other hand, borehole seismic methods are often considered a more reliable option since they provide a highly resolved $\mathrm{V}_{\mathrm{S}}$ profile with a simpler interpretation process. Nonetheless, some previous comparisons between repeated realizations of borehole methods have shown controversial results and an unexpected lack of repeatability. A systematic assessment of the performance of different seismic methods is thus crucial. Furthermore, it is also necessary to develop firm standards and guidelines for execution and interpretation of surface wave tests. Fixing a standard practice for surface-wave methods is a very challenging task because the measurements can be performed with a wide variety of experimental configurations and interpreted with an even larger spectrum of signal analysis and inversion techniques.

\section{The project}

The absence of guidelines and the recent rapid diffusion of competing methods in site characterization for engineering and seismological projects have led to a standard practice that cannot be considered satisfactory. The main scope of the InterPacific (Intercomparison of methods for site parameter and velocity profile characterization) project is to assess the reliability/variability of seismic site characterization methods (borehole and surface wave methods) used for estimating $\mathrm{V}_{\mathrm{S}}$ profile and corresponding lumped parameters (e.g., $\mathrm{V}_{\mathrm{S}, 30}$ ). The other expected outcome is a set of guidelines for performing and interpreting surface-wave tests.

Boreholes and surface wave measurements have been performed at specifying testing sites by applying different methods. As far as the surface wave methods are concerned, both active and passive surface wave data were collected while different companies have been involved for a multiple acquisitions of cross-hole, down-hole and PS-suspension logging datasets. Different participating teams have been invited for the processing and inversion of the raw experimental data. The results related to different techniques and obtained by different operators are compared in order to assess inter-method variability (difference between results from different seismic tests) and intra-method variability (repeatability of the results). These issues are of paramount importance for the assessment of uncertainty bound in seismic site response studies.

\section{The sites}

Three testing sites have been chosen: Cadarache and Grenoble in France and Mirandola in Italy (Figure 1). These sites have been selected to cover a wide range of subsoil conditions: rock, stiff soil, and soft soil.

The first site, Cadarache, is located in the CEA Cadarache research centre in the township of SaintPaul-lez-Durance, France. Cretaceous limestone is outcropping near the test site, hence this should be "rock" or "hard rock" site, with reference to subsoil seismic categories.

The second site is in the close vicinity of the "Institute Laue Langevin" nuclear research site in the town of Grenoble, France. It is a stiff-soil site since the geology consists in recent alluvial materials overlaying at few ten of meters Quaternary lacustrine clayey/marly deposits. A Mesozoic bedrock is expected at several hundred meters depth. 


\section{Amsterdam ' 14}

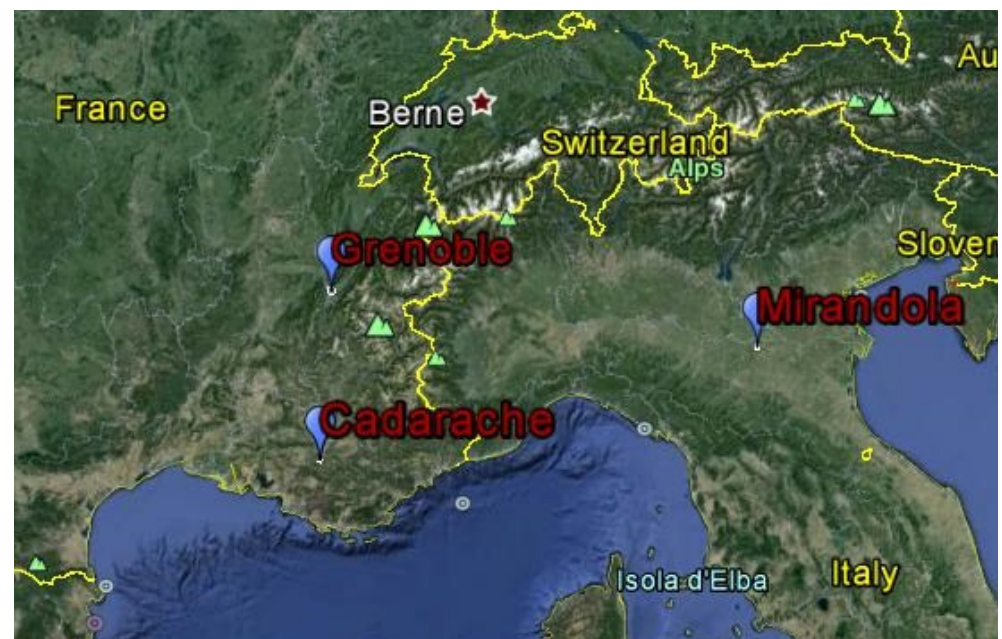

Figure 1 location of the test site: Cadarache and Grenoble in France and Mirandola in Italy.

The third site is located in the outskirt of Mirandola, a town in central Italy. This site is representative for the soft-soil class since there are alluvial deposits of different depositional environments, with alternating sequences of silty-clayey layers of alluvial plains and sandy horizons. The geological substratum consists of marine and transition deposits of lower-middle Pleistocene age and it is expected at a depth of about $100 \mathrm{~m}$.

\section{Datasets}

In all the three sites cross-hole, down-hole and PS suspension loggings were performed by at least three different companies in boreholes that were drilled within this project or within other research activities. The depth of the boreholes is equal to $30 \mathrm{~m}, 50 \mathrm{~m}$, and $123 \mathrm{~m}$ in Cadarache, Grenoble and Mirandola, respectively. A three-brorehole configuration for cross-hole tests has been realized in Cadarache and Grenoble, whereas only two boreholes are available in Mirandola.

Both active and passive surface wave data have been collected at each site in the vicinity of the boreholes.

In particular, ambient vibration acquisitions were performed with 16 Güralp broadband CM6TD seismometers with integrated digitizers in different configurations: concentric circle, triangle and Lshape. The different arrays were centered in the same common point. Circular arrays are formed by 7 equally-spaced sensors on a circumference of a given radius. Acquisitions were performed with different radii (from $5 \mathrm{~m}$ to $405 \mathrm{~m}$ ). In addition, 5 nested triangles were simultaneously collected with the side of triangle increasing from $12.5 \mathrm{~m}$ to $300 \mathrm{~m}$. The L-shape geometry is implemented locating the sensors along two perpendicular lines that cross each other at the previously identified center point. The sensors were located along the two lines with a distance that ranges from 5 to $150 \mathrm{~m}$. Even if very large arrays are not common for the seismic characterization at the depth of interest in geotechnical and earthquake engineering applications, additional arrays were acquired with wide spacing for deep investigation.

As far as the active measurements are concerned, Rayleigh wave data were acquired by using a $8 \mathrm{Kg}$ sledgehammer and 48 vertical geophones ( $4.5 \mathrm{~Hz}$ natural frequency). Different receiver spacing was adopted in each site ranging from $0.5 \mathrm{~m}$ in Cadarache to $2 \mathrm{~m}$ in Mirandola, according to space availability and expected subsoil properties. Along the same lines, SH waves were generated by using an hammer striking on an iron beam and the data were acquired using 24 horizontal geophones $(20 \mathrm{~Hz}$ natural frequency) to study the propagation of Love that may add further information to constrain the inversion process.

\section{Acknowledgments}

EdF is sponsoring the whole research project. Regione Emilia Romagna has made available the two boreholes drilled in Mirandola and the results of previous tests perfomed in this site. 